\title{
THE ROLE OF SENSE OF COHERENCE IN GROUP RELATIONS TRAINING
}

\author{
FRANS CILLIERS \\ Department of Industrial Psychology, \\ Unisa
}

\begin{abstract}
This research measured the role that sense of coherence (SOC) plays on an individual and group level during group relations training, presented to fifty-eight managers, using Antonovsky's scale and an semi-structured interview. The individual measuring high on SOC showed more understanding of group dynamics, made more use of own existing resources to cope with anxiety and found the experience challenging and meaningful, than the low measuring individual. On the group level, the split between high and low led to projective identification: the high SOC individuals contain competence and the low, incompetence. Recommendations for future group relations training are formulated.
\end{abstract}

\section{OPSOMMING}

Hierdie navorsing meet die rol wat sin vir koherensie (SOC) op individuele en groepvlak tydens groepverhoudinge opleiding speel soos aangebied vir agt-en-vyftig bestuurders, en gemeet met Antonovsky se skaal en 'n semi-gestruktureerde onderhoud. Die individu wat hoog meet op SOC toon'n beter begrip van groepdinamika, maak meer gebruik van eie bestaande hulpbronne om met angs te cope, en vind die ervaring meer uitdagend en betekenisvol, as die individu wat laag meet. Op groepsvlak lei die verdeling tussen hoog en laag na projektiewe identifikasie: die hoë SOC individue "behou" bevoegdheid en die lae, onbevoegdheid. Aanbevelings vir toekomstige groepsverhoudinge opleiding word geformuleer.

Group relations training originated about 60 years ago (Miller, 1989) and has its philosophical and theoretical roots in psychodynamics. It is based upon Freud's writings as the father of psychoanalysis (Czander, 1993), and incorporates the work of Melanie Klein on child and family psychology (De Board, 1978), Ferenczi on object relations (De Board, 1978) and Bertalanffy on systems thinking (Czander, 1993; De Board, 1978; Hirshhorn, 1993).

As a therapeutic stance it is well known and used in Psychiatry in Europe and the USA (Menzies, 1993; Miller, 1976; Obholzer \& Roberts, 1994; Rioch, 1970), has been applied in working conferences by the Tavistock Institute (Miller, 1989), developed into an organisational theory (Bion, 1961; 1970; Miller, 1976; 1983; 1993) as well as an organisational consultancy stance (Gabelnick \& Carr, 1989; Neumann et al, 1997). Internationally, its application in organisational psychology is growing amongst Industrial/Organisational psychologists, applying the stance to team building (Cilliers, 2000; Cytrynbaum \& Lee, 1993; Gabelnick \& Carr, 1989; Kets de Vries, 1991) as well as organisational consultation (Cilliers \& Koortzen, 2000a).

True to its psychodynamic nature, group relations training focuses on anxiety as the driving force of individual and group behaviour, and the unconscious defences against unwanted anxiety. As such, the model offers no clear view on psychological well-being - what Wissing and van Eeden (1994, 1997a, 1997b) refer to as the challenge presently being presented in Industrial Psychology in the training of managers and employees. This research endeavours to introduce sense of coherence as one such model of psychological well-being (Cilliers, 1988) into group relations training in order to understand its effect on individual and group behaviour.

\section{Group relations training}

This training model accepts group behaviour to be both conscious and unconscious (Miller, 1993). Conscious behaviour is clear and explicit, for example the group's set rules and observable behaviour. On the other hand, the unconscious is filled with unknown, unwanted and sometimes threatening needs and feelings, for example, about relationships of power, authority and leadership, developed collectively by the group. When this disguised and unexamined material surfaces into consciousness, the group defends against it, for example in resisting change (Coleman \& Bexton, 1975; Czander, 1993;

Requests for copies should be addressed to: T Groenewald, Technikon SA, Private Bag X6, Florida, 1710
Gabelnick \& Carr, 1989; Hircshhorn, 1993; Kets de Vries, 1991; Miller, 1993; Obholzer \& Roberts, 1994).

The basic assumptions of group relations training

Bion's (1961) three assumptions are seen as the cornerstones of group relations training (Kets de Vries, 1991; Miller, 1993; Rice, 1965; Rioch, 1970).

1. Dependency. Group members unconsciously project their dependency upon (imaginative) parental figures or systems, representing authority. If these authority figures do not respond the way the group wants them to, anger develops manifesting in counter dependence. Later the group develops to independence and interdependence.

2. Fight / flight. These are defence mechanisms the group unconsciously uses in trying to cope with discomfort. Fight reactions manifest in aggression against the self, colleagues (with envy, jealousy, competition, elimination, boycotting, rivalry, fighting for a position in the group and for privileged relationships) or the authority figure. Flight reactions manifest in the avoidance of others, threatening situations or feelings, or in rationalisation and intellectualisation.

3. Pairing. In order to cope with the anxiety of alienation and loneliness, group members try to pair with perceived powerful others or subgroups. The unconscious need is to feel secure and to create. Pairing also implies splitting up, which may happen because of experienced anxiety in a diverse work place. Typical examples of splits are black / white, male / female, senior / junior and competent / incompetent. Unconsciously the group tries to split up the whole and build a smaller system, to which the individual can belong safely and securely.

\section{Concepts in group relations training}

During group relations training, the following concepts and its behavioural dynamics are studied and learned about (Cilliers \& Koortzen, 2000b).

- Anxiety is accepted as the basis of all group behaviour (Menzies, 1993). In order to cope with its discomfort, the group unconsciously needs something or someone to contain the anxiety on its behalf, especially initially in the group's life.

- Defence mechanisms against anxiety are used in order to gain a sense of safety, security and acceptance. Rationalisation and intellectualisation may be used to stay emotionally uninvolved and in control (Gabelnick \& Carr, 1989; Neumann et al, 1997). Projection refers to the intra-system 
defensive process, where one part of the system denies and rejects feelings inherent in the unconscious image (fantasy) of the situation. It then tries to alter the uncomfortable experience by imagining that part of it belongs to another part of the system rather than to the self. It then puts good or bad (unwanted) material onto the other, thus distancing itself from the discomfort. This has no effect or influence on the target. Projection may be used to blame management for what goes wrong without management being influenced.

- Projective identification as an anxiety reducing process (Coleman \& Geller, 1985; Czander, 1993; Kets de Vries, 1991; Obholzer \& Roberts, 1994), is one of the most elusive and complicated concepts in group relations training. It refers to an inter-system, object relational interaction and process, where one part of the system (as subject) projects material into the other part (as object), who identifies with the projection (taking it on). This results in changes in both parts. The dynamics of projective identification are as follows. The subject experiences anxiety either because of its primitive envy of the object's idealised qualities and its consequent urge to destroy, spoil, dominate, devalue and control, or its wish to re-fuse with the object, or as a form of parasitism to be part of the object. It tries to relieve itself of this anxiety by externalising it, splitting off parts and internal objects of the self, leaving the self less aware of its whole and diminished by the projective loss of important aspects of itself. It requires or assigns the object to receive, identify with and contain these aspects of the self, as if it belongs to the object, but still keeps a closeness to the object. Depending on how subtle the projection is, the object may experience being manipulated into a particular role. When this behaviour predominates in the group, it becomes difficult to find other ways of coping, because it is almost impossible to think clearly, to locate sources of problems and to find appropriate and creative solutions.

- Boundaries refer to the physical and psychological borders around the group in order to contain its anxiety, thus making the group controllable, safe and contained (Cytrynbaum \& Lee, 1993; Czander, 1993; Hirschhorn, 1993; Kets de Vries, 1991; Miller, 1993; Neumann et al, 1997).

- Representation refers to when a member consciously or unconsciously negotiates a boundary, acting on behalf of the group (for example in crossing, resisting or erecting a boundary). If the individual's authority boundaries are unclear, the high level of anxiety tends to immobilise and disempower him/her. The group leans firstly how it normally disempowers its representatives and secondly, new ways of empowering them in order to work more effectively on behalf of the group (Kets de Vries, 1991; Obholzer \& Roberts, 1994).

- Authorisation refers to empowering a group member to act on behalf of the group in the role of observer, delegate or plenipotentiary (Czander, 1993; Obholzer \& Roberts, 1994).

- Leadership is described as managing what is inside the boundary in relation to what is outside. This can happen inside the individual (without followers) or by one group member on behalf of the followership (Gabelnick \& Carr, 1989; Obholzer \& Roberts, 1994).

- Relationship between group members, refers to any type of face-to-face interaction, as it happens in the here-and-now. Unconsciously, the group member is always in relatedness to the group, also called "the group in the mind" (Gabelnick \& Carr, 1989; Neumann et al, 1997; Shapiro \& Carr, 1991) .

- Group as a whole refers to collectivism - one part of the system acting, or containing emotional energy, on behalf of another. This implies that no event happens in isolation and that there is no co-incidence but rather synchronicity in the behaviour of the group (Wells, 1980).

The group relations training event

The Tavistock (also called Leicester) model (Miller, 1989, 1993) is used in structuring the group relations training event. The primary task of the event is to provide opportunities for the group to study its own behaviour in the here-and-now. This is an educational task consisting of experiential learning subevents, namely (for example in this research) plenaries, small, discussion, review and application groups, each with its own task, described as follows.

- Plenary - to provide the opportunity for all members to share information about the learning within the group experience.

- Small group - to provide opportunities for the group to learn about its own behaviour in the here-and-now.

- Discussion group - to provide opportunities for the group to learn about the concepts in the group relations training model and to relate theory to practice.

- Review / application group - to provide opportunities for the group to review their learning during the total event and then to ork towards the application of the learning to their roles in their everyday working life.

The group relations training consultant is actively involved in the event, formulating working hypothesis and interpreting behaviour processes and dynamics in the here-and-now, on the basis of his/her own observations, experience and expertise. $\mathrm{He} / \mathrm{she}$ also takes responsibility and authority to provide the boundary conditions of task, space (also called territory) nd time, in such a way that all participants can engage with the primary task (Miller, 1989, 1993).

\section{Sense of coherence (SOC)}

The salutogenic paradigm (Antonovsky, 1979, 1984) focuses on the origins of health and well-ness, the locating and developing of personal and social resources and adaptive tendencies which relate to the individual's disposition, allowing him/her to select appropriate strategies to deal with confronting stressors and anxieties. Sense of coherence is defined (Antonovsky, 1984,1987) as a global orientation that expresses the extent to which the individual has a pervasive, enduring, though dynamic feeling of coherence, that (1) the stimuli deriving from his/her internal and external environments in the course of living are structured, predictable, and explicable, (2) the resources are available to meet the demands posed by these stimuli, and (3) these demands are challenges worthy of investment and engagement.

The strength of the SOC is connected to a variety of coping mechanisms, called generalised resistance resources (GRR's) (Antonovsky, 1979), defined as any characteristic of the individual, a group, or the environment that can facilitate effective tension management. This enhances the disposition to select appropriate strategies in dealing with and confronting stress and anxiety. A high SOC indicates a readiness and willingness to tap into these resources at his/her potential disposal, leading to a cognitive and emotional appraisal of the world, again leading to effective coping, health enhancement and social adjustment.

SOC consists of the following three dimensions (Antonovsky, 1987).

1. Comprehensibility refers to the extent to which the individual perceives confronting stimuli deriving from the internal and external environments, as making cognitive sense, as information that is ordered, consistent, structured and clear, rather than as noisy, chaotic, disordered, random, accidental and inexplicable.

2. Manageability refers to the extent to which the individual perceives that resources at his/her disposal are adequate to meet the demands posed by the bombarding stimuli, events are perceived as bearable that can be coped with and that challenges can be met.

3. Meaningfulness refers to the extent to which the individual feels that life makes emotional sense. In terms of motivation, problems and anxieties posed by life are seen as challenges, providing stimulation to invest energy and in turn elicit commitment and engagement. The individual sees life as meaningful, and problems / events are viewed as challenges worthy of emotional investment and commitment.

\section{Integration}

Working in and learning about groups is often confusing and stressful (Rugel \& Meyer, 1984) particularly in unstructured situations when sometimes, seemingly no one knows what is going on. Central to this learning process is the repeated dis- 
covery of the presence of irrational and unconscious processes that interfere with attempts to manage oneself, the group, tasks and roles in a conscious and rational way (Obholzer \& Roberts, 1994). Uncomfortable and threatening feelings are painful to acknowledge and stirs up a high level of anxiety which the group defends against (for example by avoiding), exacerbating stress rather than alleviating it.

For the individual, this can be an overwhelming as well as an empowering experience. The mental pains experienced in working from a group relations stance have to be dealt with by the individual, each with his/her own personal history of having developed ways of managing or evading situations of anxiety, pain, fear, confusion and depression (Obholzer \& Roberts, 1994). The ability to contain a spectrum of painful emotions generated in this way is psychologically difficult. Conversely, this experience facilitates an opportunity to understand the deep and complex group dynamics in terms of authority and leadership, which is essential to the understanding of organisational functioning and dynamics. It illuminates some of the difficulties in managing oneself, managing the self at work, as well as in being managed and managing others (Obholzer \& Roberts, 1994).

Although there are certain stress situations that are likely to induce anxiety no matter what coping mechanisms an individual has at his/her disposal or to what extent he/she has a disposition to respond with anxiety (Antonovsky \& Sagy, 1986), evidence exist within the salutogenic paradigm, that a high level of SOC facilitates the individual's psychological and/or physiological coping responses to a controlled stressful situation (McSherry \& Holm, 1994). Antonovsky (1987) adds that it is the strength of the SOC of the person experiencing such events that will determine whether the outcomes will be noxious, neutral, or salutary. He emphasises that the strength of an individual's SOC is central to the regulation of emotional tension generated by confrontation with stressors.

No research findings could be traced linking group relations training to salutogenic functioning or SOC. From the above it can be expected that an individual with a high SOC will cope differently, hopefully "better" with the stress and anxiety of a group relations training event, than an individual with a low SOC. Proof about this expectation can contribute towards an understanding of how employees cope in stressful relational work situations (see Obholzer \& Roberts, 1994).

\section{Research question, aim, research design and hypothesis}

The research question can be stated as, what role does SOC play in coping with the demands of a group relations training event? The aim of the research is to ascertain the extent of this role in an actual group relations training event and to formulate recommendations from the findings for application in the fields of group and interpersonal training and development.

Action research will be done in the presentation of a group relations training event, quantitative research in the measurement of SOC and qualitative research in the form of an interview with the participants. The independent variable is the group relations training event and the dependent variable is SOC. The research hypothesis is that there is a relationship between a low SOC score and experienced non-coping with the demands of group relations training, or between a high SOC score and experienced coping.

\section{METHOD}

\section{The sample}

Convenient sampling was used (Anastasi \& Urbina, 1997). A general invitation to managers to participate in a group relations training event was addressed to the Human Resources Departments of 12 large semi-government and private organisations in Gauteng. Of the 82 who responded, 58 could attend the event. The mean age was 33 years. The gender ratio was 25 (male $43 \%$ ) / 33 (female - 57\%). Blacks, coloureds, Indians and whites were included, although not representative of the total South African demographic scenario.

\section{The group relations training event}

The event was structured and presented as discussed above. This took place over three working days, each consisting of four sessions of 90 minutes each and a 30 minute end-of-day integration session, totalling 19,5 hours as set out in Table 1 . The author (having had extensive training and experience in the Tavistock stance) acted in the role of consultant.

TABLE 1

THE GROUP RELATIONS TRAINING EVENT PROGRAMME

\begin{tabular}{llll}
\hline TIME & DAY 1 & DAY 2 & DAY 3 \\
\hline 08:30-10:00 & $\begin{array}{l}\text { Opening plenary } \\
\text { Small group 1 }\end{array}$ & Small group 5 & Small group 8 \\
& Tea & Tea \\
10:00-10:30 & Tea & Discussion 2 & Review group 2 \\
10:30-12:00 & Small group 2 & Lunch & Lunch \\
12:00-13:00 & Lunch & Small group 6 & Application group \\
13:00-14:30 & Small group 3 & Tea & Tea \\
14:30-15:00 & Tea & Small group 7 & Discussion 2 \\
15:00-16:30 & Small group 4 & Review group 1 & Closing plenary \\
16:30-17:00 & Discussion 1 & & \\
\hline
\end{tabular}

\section{Measurement}

(1) SOC was measured by means of Antonovsky's (1987) 29item Sense of Coherence Scale. This provides a total as well as sub-scores for the three dimensions. The scale has satisfactory levels of reliability and validity (Antonovsky, 1987). (2) Afterwards, a 30 minute tape recorded and unstructured interview was conducted by the author. The aim of the interview was to ascertain the training experience of the individual by asking a single question, namely: "What was your experience of the group relations training event?". The interview was transcribed and a content analysis (Strauss \& Corbin, 1990) and open coding (breaking down, examining, comparing, conceptualising and categorising of data) were done. The manifesting main and sub themes were determined (Jones, 1996, Kerlinger, 1986) for each individual, distinguishing between the absence and presence of SOC characteristics. Validity and reliability was ensured by having the results examined by a psychologist, to whom this technique is well known. It was declared correct.

\section{Procedure}

The sample of 58 was divided (1) randomly and (2) to fit their work schedules, into five groups. Thus, the group relations training event was presented five times with groups ranging between nine and 12 members. The SOC scale was administered to each participant beforehand and then the group relations training event was presented. The day after, the interview was conducted with each participant. Next, the SOC scales were marked (this was done after the training event, to ensure that the outcome did not influence the experience of participants or consultants during the event). Individual participant's total SOC scores were ranked from low to high (resulting in a fairly normal distribution). The ten individual scores on the lower end of the continuum were sub-grouped and called the "low SOC subgroup" and the ten individual scores on the high end of the continuum were sub-grouped and called the "high SOC subgroup". The rest is referred to as the "middle group". Then, t-tests were done by means of the SAS programme (SAS, 1985) to ascertain the significance of difference between the low and the high subgroups. Lastly, each individual participant's total as well as dimension SOC scores were matched with his/her interview themes and interpreted.

\section{RESULTS}

The qualitative interpretation of the middle group's experience and learning is that low SOC is associated with confusion and difficulty in learning and high SOC with meaningfulness and insight into group dynamics and personal learning. Table 2 contains the t-test results, indicating a significant difference between the low and high subgroups. This meant that the low and high interview results could be interpreted with validity. 
The interviews elicited the themes of anxiety, defence mechanisms, feelings, making sense out of the experience and learning outcomes.

TABLE 2

T-TEST RESUTS THE SIGNIFICANCE OF DIFFERENCE BETWEEN THE LOW AND HIGH SOC SUBGROUPS

\begin{tabular}{lllll}
\hline Subgroup & N & T & DF & Probability \\
\hline Low SOC & 10 & $-16,89$ & 7,8 & 0,00 \\
High SOC & 10 & $-16,89$ & 8,1 & 0,00 \\
\hline
\end{tabular}

Individuals in the low SOC subgroup reported the following experiences.

1. Anxiety. They described the event as filled with confusion and difficulty (anxiety). It was as if the total group had put them within a boundary and made them contain the anxiety on its behalf. Thus, they became powerless to move out of the boundary.

2. Defence mechanisms. They used fight and flight reactions. During the event, they projected their anger onto the consultant - this behaviour continued during the interviews afterwards. They projected their fear of punishment, being rejected, judged and not being trusted, onto the group and its members. Their communication was cognitive, focused on the self and presented in there-and-then terms. This defence took up a lot of energy which resulted in further difficulty to focus on and learn about what was happening in the group. They became the representation of passive resistance for the group.

3. Feelings. They experienced uncomfortable feelings of confusion, fear, being lost, conflict, suspicion, jealousy, guilt, irritation, frustration, reluctance, powerlessness, paralysis, they were drained of energy and had a lack of confidence. They were preoccupied with their own individual needs and struggles, which made it difficult to see "the bigger group picture". They reported a sense of being pushed by outside (of their control) forces into doing and even saying things on the group's behalf.

4. Making sense out of the experience. They reported difficulty in making sense, describing the event as unfulfilled, a waste of time, and not meeting their expectations. As individuals in this subgroup, they got stuck in dependance which bonded them together and gave them some identity and boundary. It may be that they became the dumping ground for the group's ineffectiveness.

5. Learning outcomes. They mentioned their learning in vague and general terms, for example "to listen more carefully" (which could indicate heightened suspicion), "to try to get more in contact with myself" (indicating a lack of coherence), "to learn more about boundaries" (indicating not being able to manage their own learning during the event), and "different things mean different things to different people" (indicating anxiety, confusion and difficulty to become part of the event, struggling to integrate the experience). It is as if they got stuck in the role of follower as well as in the splits manifesting in the group.

Individuals in the high SOC subgroup reported the following experiences.

1. Anxiety. Initially a high level of anxiety was experienced, but differently form the previous subgroup, these individuals started to show insight into the group's behaviour and dynamics as well as the own life it was creating - this started happening about halfway through the event. They managed to work with the concept of "group as whole", thus understanding the object relations in the group. After they have started to own and verbalise their anxiety in the group experience, they could start listening to themselves and to other group members.

2. Defence mechanisms. They were inclined to intellectualise (more than project) and their fight and flight reactions decreased as the event progressed.
3. Feelings. They mentioned uncomfortable feelings such as anxiety, anger, frustration, insecurity and stress, and at the same time tried to stay positive, being intrigued by what is happening in the group, and feeling adventurous. Thus, they could own their feelings and start taking personal responsibility for their learning.

4. Making sense out of the experience. They focused on the behavioural processes which facilitated their understanding of the dynamic nature of the group's behaviour. They authorised themselves to shift their boundaries and to work with the consultant (instead of against him) towards interdependence. Thus they could start attending to other objects and splits in the group, such as the talking versus the silent members, and the learning versus the "not understanding" members.

5. Learning outcomes. They reported an increased awareness of how to build relationships within the group boundary, finding their own role in the group as well as in groups they belong to outside of the event. They referred to having more insight into their own working groups and feeling more empowered to work more effectively in them. They reported their awareness about having to make important career decisions with less fear and dis-empowerment.

The following integration in terms of the SOC dimensions can be made.

1. Comprehensibility

- The low SOC subgroup had difficulty in coping with the event - it did not make cognitive sense to them, it was without direction, disordered, chaotic, unpredictable and a waste of time. They focussed on the content and rejected many of the consultant's interpretations of symbols, metaphors and the manifesting group dynamics - for them it was coincidental, accidental, irrelevant and it had nothing to do with the group's unconscious.

- The high SOC subgroup expressed surprise and intrigue at the group's dynamics. Initially they found it difficult to understand, but focussing on their own authority issues increased their ability to work with (instead of against) the interpretations of the consultant as an authority figure. This facilitated an understanding of the dynamics and an experience of the event as clear, ordered and meaningful. They reported more confidence in venturing their own interpretations of the dynamics towards the end of the event, including working with complex terminology such as the splits, defences, boundaries, relatedness, group as a whole as well as the manifesting object relationships.

2. Manageability

- The low SOC subgroup experienced a high level of anxiety which led to the immobilisation of their resistance resources. They felt powerless to influence the course of events and their own learning. This finding is consistent with Antonovsky's (1987) view that a low sense of manageability will lead to feelings of victimisation (vexed and irritable) and a sense that life is treating one unfairly.

- The high SOC subgroup started to make use of their own and the group's resistance resources, helping them to meet the demands of this difficult kind of training with its focus on the unconscious. Their framing of the event as a challenge and the trusting of their own resources, turned the event into a manageable learning experience.

3. Meaningfulness

- The low SOC subgroup could not make a lot of emotional sense out of the experience. It is as if their emotional energy was consumed and they were immobilised by the high level of anxiety. Therefore they did not show a commitment or strong engagement in the group's activities and found the event not to be meaningful.

- The high SOC subgroup saw the initial difficulty and uncomfortable feelings as a challenge. Because they invested emotional energy into the event, their commitment and engagement increased. They reported that the training event was meaningful on a personal, a group, as well as on 
an organisational learning level. The experience of emotional sensibility lead to a sense of empowerment to shape their own experiences as well as their destiny.

\section{DISCUSSION}

The results indicate a qualitative difference between the individual with low and high SOC. The latter reports more learning from the group relations training in terms of an understanding of the group's behaviour and dynamics, the employment of his/her own existing resources and the finding of meaning in the nature of group dynamics, than the first mentioned. Therefore, the research hypothesis is accepted.

On the group level the results indicate that projective identification as a group dynamic phenomenon, had a strong influence on the experience and learning of both the extremely low and high SOC individuals as designated subgroups. The total groups anxiety around performance and competitiveness in the training situation was externalised, splitting off parts of the total and leading to a loss of synergy and integrative learning for the whole group. The less the low SOC subgroup copes and learns, the more the high SOC subgroup does. According to Knapp (1989), the part of the system most susceptible to projections will be most dependent, needy, or the least differentiated. This means that the learning about group relations during this event was probably equally difficult for both extremes of low and high SOC and relatively easier for the middle group.

$\star$ In the collective unconscious, the low SOC subgroup's lack of comprehensibility, manageability and meaningfulness upon entrance into the event, became an object of non-coping, receiving projections of what was unacceptable in the competition, and was then manipulated into containing powerlessness, stuck-ness, resistance and eventually incompetence. The resulting discomfort in representing the dark side of the system lead to envy towards the opposite position, and a consequent urge to re-unite with the high SOC subgroup as an object of competence in order to learn from it. But this was resisted by the object of competence, increasing the frustration about not learning.

* In the collective unconscious, the high SOC subgroup's comprehensibility, manageability and meaningfulness upon entrance into the event, became an object of coping, receiving projections of what was acceptable in the competition, and was then manipulated into containing power and competence. This privileged, envious, powerful and heroic position lead to a resistance to fuse with the incompetent object and resulted in becoming even more competent. This defence against the pain of identifying with the incompetence in the self, restricts one's own learning. It can be interpreted as "feeling on a high" about one's own learning, but because it was projected (not earned) it cannot be fully owned, internalised or valued.

The above mutual projected and emotional dependance of the low and the high SOC subgroups, indicate that both carried a burden on behalf of the other. This may result in restricted learning for both, although clearly more restricted and even prohibitive for the low SOC subgroup. The middle group seem to have played a pivotal role in the incompetence / competence split. These individuals reported an expected variety of learning about themselves and group behaviour, congruent to their level of SOC. They probably learned most of all the participants in the group relations training event.

This research illustrates that the individual's SOC acts as a facilitating condition in learning within group relations training. At the same time the individual's learning is influenced by group dynamic factors beyond his/her control. These projections need to be discussed and processed during the event in order for the individual to optimise his/her own learning. The individual needs to become aware of what characteristics (needs, expectations, personality traits) he/she came into the training event with, and that he/she can distinguish between what his/her own and personal learning experience is, and what is projected ("dumped") onto and into him/her by the group's unconscious (to carry as a container). In terms of group behaviour as applied to team building for example, it illustrates that a training group may split itself between low and high functioning and performance, leading to the impression that one subgroup is not working, while others are star performers. In reality, both may have difficulty in performing their tasks. Consultants should be aware of this dynamic behaviour and ensure that the group addresses its polarisations, relating to competence and contribution. Only when these projections are owned, taken back and processed, the group can work towards synergy, finding new ways of coping, clear thinking, problem solving leading to clear and creative solutions and work performance.

It is recommended that future research includes the role of other salutogenic constructs (as mentioned by Strümpfer, 1990;1995) as well as psychological optimality constructs (as mentioned by Cilliers, 1988).

\section{REFERENCES}

Anastasi, A. \& Urbina, S. (1997). Psychological testing. Upper Saddle River: Prentice-Hall.

Antonovsky, A. (1979). Health, stress and coping. San Francisco: Jossey-Bass.

Antonovsky, A. (1984). A call for a new question - salutogenesis - and a proposed answer - The sense of coherence. Journal of Preventive Psychiatry, 2,1-13.

Antonovsky, A. (1987). Unraveling the mystery of health: How people manage stress and stay well. San Francisco: Jossey-Bass.

Antonovsky, H. \& Sagy, S. (1986). The development of a sense of coherence and its impact on responses to stress situations. Journal of Social Psychology, 126(2), 213-225.

Bion, W.R. (1961). Experiences in groups. London: Tavistock Publications.

Bion, W.R. (1970). Attention and interpretation. London: Tavistock Publications.

Cilliers, F. (1988). The concept psychological optimality in management. IPM Journal, 7(5), 15-18.

Cilliers, F. (2000). Team building from a psychodynamic approach. Journal of Industrial Psychology, 26(1), 18-23.

Cilliers, F. \& Koortzen, P. (2000a). Consulting form a psychodynamic stance. Paper presented at the national congress of the Society for Industrial Psychology, Pretoria.

Cilliers, F. \& Koortzen, P. (2000b). The psychodynamic view on organisational behaviour. The Industrial-Organizational Psychologist, 38(1), 59-67.

Colman, A.D. \& Bexton, W.H. (1975). Groups Relations Reader 1 Jupiter: A.K. Rice Institute.

Colman, A.D. \& Geller, M.H. (1985). Group relations reader 2. Jupiter: The A.K. Rice Institute.

Cytrynbaum, S. \& Lee, S.A. (1993). Transformations in global and organizational systems. Jupiter: A.K. Rice Institute.

Czander, W.M. (1993). The psychodynamics of work and organisations. New York: Guilford Press.

De Board, R. (1978). The psychoanalysis of organisations. London: Routledge.

Gabelnick, F. \& Carr, A.W. (1989). Contributions to social and political science. Jupiter: A.K. Rice Institute.

Hirschhorn, L. (1993). The workplace within: Psychodynamics of organizational life. Cambridge: MIT Press.

Jones, R.A. (1996). Research methods in the social and behavioural sciences. Sunderland: Sinauer.

Kerlinger, F.N. (1986). Foundations of behavioural research. Hong Kong: Holt, Rinehart \& Winston.

Kets De Vries, F.R. (1991). Organizations on the couch: Handbook of psychoanalysis and management. New York: Jossey-Bass.

Knapp, H. (1989). Projective identification: Whose projection whose identity. Psychoanalytic Psychology, 6(1), 47-59.

McSherry, W.C. \& Holm, J. (1994). Sense of coherence: Its effects on psychological and physiological processes prior to, during, after a stressful situation. Journal of Clinical Psychology, 50(4), 476-487.

Menzies, I.E.P. (1993). The functioning of social systems as a defence against anxiety. London: Tavistock Institute of Human Relations. 
Miller, E.J. (1976). Task and organisation. New York: Wiley.

Miller, E.J. (1983). Work and creativity. Occasional Paper No 6. London: Tavistock Institute of Human Relations.

Miller, E.J. (1989). The "Leicester" Model: Experiential study of group and organisational processes. Occasional Paper No. 10. London: Tavistock Institute of Human Relations.

Miller, E.J. (1993). From dependency to autonomy: Studies in organization and change. London: Free Association Books.

Neumann, J.E., Kellner, K. \& Dawson-Shepherd, A. (1997). Developing organisational consultancy. London: Routledge.

Obholzer, A. \& Roberts, V.Z. (1994). The unconscious at work. London: Routledge.

Rice, A.K. (1965). Learning for leadership. London: Tavistock Publications.

Rioch, M.J. (1970). Group relations: Rationale and technique. International Journal of Group Psychotherapy, 20, 340-355.

Rugel, R.P. \& Meyer, D.J. (1984). The Tavistock group experience, findings and implications for group therapy. Small Group Behaviour, 15(3), 361-374.

SAS Institute. (1985). SAS user's guide: statistics, version 5 edition. Cary: SAS Institute.

Shapiro, E.R. \& Carr, A.W. (1991). Lost in familiar places: Creating new connections between the individual and society. London: Yale University Press.
Strauss, A. \& Corbin, J. (1990). Basics of qualitative research: Grounded theory. Procedures and techniques. Newbury Park: Sage.

Strümpfer, D.J.W. (1990). Salutogenesis: A new paradigm. South African Journal of Psychology, 20 (4), 265-276.

Strümpfer, D.J.W. (1995). The origins of health and strength: From 'salutogenesis' to 'fortigenesis'. South African Journal of Psychology, 25 (2), 81-89.

Wells, L. (1980). The group-as-a-whole: A systemic socio-analytical perspective on interpersonal and group relations. In Alderfer, C.P. \& Cooper, C.L. (Eds). Advances in experiential social processes, 2, 165-198.

Wissing, M.P. \& Van Eeden, C. (1994). Psychological wellbeing: Measurement and construct clarification. Paper presented at the 23rd international congress of Applied Psychology, Madrid.

Wissing, M.P. \& Van Eeden, E. (1997a). Facing the challenge to explicate mental health salutogenically: Sense of coherence and psychological well-being. Paper presented at the 55th annual convention of the International Council of Psychology, Graz.

Wissing, M.P. \& Van Eeden, E. (1997b). Psychological well-being: A fortigenic conceptualisation and empirical clarification. Paper presented at the congress of the Psychological Sociery of South Africa, Durban. 